\section{THE PLACE OF MATHEMATICS IN ENGINEERING PRACTICE. ${ }^{1}$}

THE foundations of modern engineering have been

laid on mathematics and physical science; the practice of engineering is now governed by scientific methods applied to the analysis of experience and the results of experimental research. Engineering has been defined as "the art of directing the great sources of power in nature for the use and convenience of man." An adequate acquaintance with the laws of nature, and obedience to those laws, are essential to the full utilisation of these sources of power. It is now universally recognised that the educated engineer must possess a good knowledge of the sciences which bear upon his professional duties, in combination with thorough practical training and experience in actual engineering work. Neither side of his education can be neglected without hampering him seriously, especially when he has to go beyond precedent and face new problems. Of these sciences, the mathematical is undoubtedly of the greatest importance to engineers. The range and character of mathematical knowledge which can be considered adequate are gradually being agreed upon as experience is enlarged; and present ideas are embodied in the courses of study prescribed in the calendars of schools of engineering. Absolute identity in the course of study and the standards laid down for degrees in engineering has not been attained, but the approach thereto has already been considerable, and the movement will undoubtedly continue in the same direction.

The preponderance of opinion amongst engineers now favours the teaching to students of engineering of science generally, and of mathematics in particular, being undertaken by recognised authorities in the several branches, and on lines which shall ensure greater breadth of view and fuller capability for dealing with new problems arising in their professional work than can be secured by means of special courses of instruction arranged for students of engineering as a class apart. Whatever brancn of engineering a man may select for his individual practice, he must need a fundamental knowledge of mathematics, and in some branches, in order to do his work well, he will require to add considerably to the mathematical knowledge which is sufficient for a degree.

As time passes the mathematician and the practising engineer have come to understand one another better, and to be mutually helpful. While engineers as a class cannot claim to have made many important or original contributions to mathematical science, some men trained as engineers have done notable work of a mathematical character. The names of Rankine, William Froude, and John Hopkinson among British engineers also hold an honoured place in mathematics. Mathematicians of eminence have spent their lives in the tuition of engineers, and in that way have greatly influenced the practice of engineering; but while they have necessarily become familiar with the problems of engineering as a consequence of their connection therewith, they have not accomplished much actual engineering work, and none of it has been of first importance. Speaking broadly, there is an abiding distinction between mathematicians and engineers. Mathematicians regard engineering chiefly from the scientific point of view, and are primarily concerned with the bearing of mathematics on engineering practice, the construction of theories, and the framing of useful rules. Engineers, even when well equipped with mathematical knowledge, are primarily devoted to the design and construction of

1 Lecture delivered at Cambridge before the Fifth International Congress of Mathematicians by Sir William H. White, K.C.B., F.R.S. efficient and durable works, their main object being to secure the best possible association of efficiency and economy, and so to achieve practical and commercial success. There is evidently room for both classes, and their collaboration in modern times has produced wonderful results.

The proper use of mathematics in engineering practice is now generally agreed to include the following steps: first comes the development of a mathematical theory based on assumptions which are thought to embody and to represent conditions disclosed by past practice and observation. Frequently these theoretical investigations give rise to valuable suggestions for further observation or experimental investigations. Mathematical analysis must be applied to the results of observation and experiment; and, as a result, amendments or extensions are made of the original mathematical theory. Useful rules are also devised, in many instances, which serve for guidance in the future practice of engineers. Formerly it was thought by men of science that purely mathematical investigation and reasoning would do all that was required for the guidance of engineering practice; now it is admitted that such investigations will not suffice, and that the chief services which can be rendered to engineering by mathematicians will consist in the suggestion of the best directions and methods for experimental research, the conduct of observations on the behaviour of existing works, the establishment of general principles based on analysis of experience, and the framing of practical rules embodying scientific principles.

The contrast between present and past methods can be illustrated by comparing investigations made during the eighteenth century into the behaviour of ships amongst waves by Daniel Bernoulli, who won the prize offered by the Royal French Academy of Science in 1757, and work done by William Froude a century later in connection with the same subjects. Bernoulli was the greater mathematician, but had only a small knowledge of the sea and of ships. His memoir was a mathematical treatise; his practical rules, although deduced from mathematical investigations which were themselves correct, depended upon certain fundamental assumptions which did not correctly represent either the phenomena of wavemotion or the causes producing and limiting the rolling oscillations of ships. Bernoulli realised and dwelt upon the need for further experiment and observation and showed remarkable insight into what was needed; but the fact remains that he neither made such experiments himself nor was able to induce others to make them. As a consequence, his practical rules for the guidance of naval architects were incorrect and would have produced mischievous results if they had been applied in practice.

William Froude was a trained engineer who had a good knowledge of mathematics and a mathematical mind. His acquaintance with the sea and ships was considerable, his skill as an experimentalist was remarkable, and he was fortunate enough to secure the support of the Admiralty through the Constructive Department. He thus obtained the services of the officers of the Royal Navy in making a long series of accurate and detailed observations of the characteristic features of ocean waves as well as the rolling of ships amongst waves or in still water. In this way, starting with the formulation of a mathematical theory of wave-motion, and of a theory for unresisted rolling in still water and amongst waves, Froude added corrections based on experimental research, and succeeded eventually in devising methods by means of which naval architects can make close approximations to the probable behaviour of ships of new design when exposed to the action of waves.

NO. 2238, vor. 90$]$ 
either forming a regular series or constituting an irregular sea. In these approximations allowance can be made for the effect of water-resistance to the rolling motion--a most important factor in the problem which could not be dealt with until experimental research had been made, and results had been subjected to mathematical analysis. In addition, Froude laid down certain practical rules for the guidance of naval architects, and the application of these rules has been shown by long experience to favour the steadinessthat is to say, the comparative freedom from rollingof ships designed in accordance with these rules. In short, a problem which had proved too difficult when attacked by Daniel Bernoulli in purely mathematical fashion was practically solved a century later by Froude, who employed a combination of mathematical treatment and experimental research.

Another example of the contrast between earlier and present methods is to be found in the treatment of the resistance offered by water to the onward motion of ships. From an early date mathematicians have been attracted to this subject, and many attempts were made to frame mathematical theories. When steam-propulsion for ships was introduced, the matter became of great practical importance, because it was necessary to make estimates for the engine-power required to drive a ship at the desired speed. In making such estimates it was necessary to approximate to the value of the water-resistance at that speed, although the required engine-power was also influenced by the efficiency of the propelling apparatus and propellers. In addition, it was obvious that the water-resistance to the motion of a ship when she was driven by her propellers at a given speed would be in excess of the resistance experienced if she were towed at the same speed, and there was no exact knowledge in regard to that increment of resistance. The earlier mathematical theories of resistance proved to be of little or no service, and they were based on erroneous and incomplete assumptions. Rankine devised a "streamline" theory which was superior to its predecessors, but it also for a time had no effect on the practice of naval architects. William Froude, adopting this stream-line theory, dealt separately with frictional resistance, and devised a "law of comparison" at corresponding speeds, by which from the "residual resistance" of models-exclusive of friction-it became Dossible to estimate the corresponding residual resistance for ships of similar forms. At first he stood alone in advocating these views, but subsequent experience during forty years has demonstrated their soundness.

Experimental tanks for testing models of ships, such as Froude introduced, are now established in all maritime countries, and the results obtained therein are of enormous value to the designing of steamships. In regard to the selection of the forms of ships, naval architects are now able to proceed with practical certainty; but in connection with the design of screw propellers, even after model experiments have been made with alternative forms of screws, there is still great uncertainty, and dependence upon the results obtained on "progressive" speed trials of ships is still of the greatest service. As yet the "law of comparison" between model screws and full-sized screws has not been determined accurately. The condition of the water in which screws act, as influenced by the advance of a ship and her frictional wake, the phenomena attending the passage of the water through a screw, and the impression thereon of sternward motion from which results the thrust of the propeller, the effect upon that thrust of variations in the forms and areas of the blades of screw propellers, and the causes of "cavitation," all form subjects demanding further investigation. In these cases the only hope of finding NO. 2238, VOL. 90] solutions lies in the association of experimental research with mathematical analysis. There have been very many mathematical theories of the action of screw propellers, but none of these has provided the means for dealing practically with the problems of propeller design, and there is no hope that any purely mathematical investigation ever will do so, because the conditions which should be included in the fundamental equations are complex and to a great extent undetermined.

In connection with other branches of engineering, model-experiments have also proved effective. Examples are to be found in connection with the estimates for wind-pressure on complicated engineering structures, such as girder or cantilever bridges. Experimental methods are also being applied with great advantage to the study of aeronautics and the problems of flight.

The association of the mathematical analysis of past experience with designs for new engineering works of all kinds is both necessary and fruitful of benefits. A striking example of this procedure is to be found in connection with the structural arrangements of ships of unprecedented size, which have to be propelled at high speeds through the roughest seas, to carry heavy loads, to be exposed to great and rapid changes in the distribution of weight and buoyancy, and to be subjected simultaneously to rolling, pitching, and heavy motion, as well as to blows of the sea. In such a case purely mathematical investigation would be useless; the scientific interpretation of past experience and the comparison of results of calculations based on reasonable hypotheses for ships which have seen service with similar results of calculations for ships of new design are the only means which can furnish guidance.

In the past the association of mathematicians and engineers has done much towards securing remarkable advances in engineering practice; and in future it may be anticipated that still greater results will be attained now that the true place of mathematicians in that practice is better understood and utilised.

\section{UNIVERSITY AND EDUCATIONAL INTELLIGENCE.}

A GREAT cause of anxiety to those who are responsible for evening continuation schools and classes lies in the spasmodic attendances and lack of continuity of the casual student. The prospectus of the Municipal Technical Institute, Belfast, shows that the authorities in that city deal with this source of trouble courageously. Students must submit to an entrance examination, and must follow a course of study, and "any student who does not wish to conform to the regulation as to attending a definite course of study or passing the entrance examination can obtain exemption on making application at the office and paying treble the fee for the class it is desired to join." Side by side with these restrictions there is every opportunity and incentive to the serious student to equip himself thoroughly for his business.

The London County Council announces that the evening classes held in Polytechnics, technical institutes, schools of art, commercial centres, and evening schools will shortly be reopened. The programme which the Council has prepared includes classes to meet all kinds of needs. The enrolment of students began on Monday, September 16, and a leaflet giving full particulars as to where the classes are held, and as to fees (which it may be stated are very low), can 